\title{
Comparison of three clinical and three ultrasonic equations in predicting fetal birth weight
}

\author{
Renuka Malik $^{1 *}$, Pooja Thakur $^{2}$, Garima Agarwal $^{1}$
}

\author{
${ }^{1}$ Department of Obstetrics \& Gynaecology, PGIMER, RML Hospital, New Delhi, India \\ ${ }^{2}$ Department of Obstetrics \& Gynaecology, ESI Hospital, New Delhi, India
}

Received: 08 December 2015

Revised: 14 December 2015

Accepted: 22 December 2015

\author{
*Correspondence: \\ Dr. Renuka Malik, \\ E-mail: renucam@yahoo.co.in
}

Copyright: (c) the author(s), publisher and licensee Medip Academy. This is an open-access article distributed under the terms of the Creative Commons Attribution Non-Commercial License, which permits unrestricted non-commercial use, distribution, and reproduction in any medium, provided the original work is properly cited.

\begin{abstract}
Background: Antenatal assessment of fetal weight is important part in the management decisions during labour, thereby improving perinatal outcome. There are a large number of clinical methods and ultrasonic formulae for predicting fetal birth weight (EBW) with varying degrees of accuracy. This study was an attempt to compare the accuracy of three clinical and three ultrasonic methods in Indian population. The method with highest accuracy can be used in high and low resource setting in a country like ours with diverse resource settings.

Methods: This was a prospective non randomized cohort study done on 100 antenatal patients in PGIMER, Dr. RML Hospital; New Delhi from Nov 2011 to Jan 2013 EBW (Expected Birth Weight) was calculated applying the 6 formulae three clinical and three ultrasonic and statistical analysis done after delivery comparing with ABW (Actual Birth Weight).

Results: Accuracy in all ABW within $10 \%$ of ABW was $94 \%$ with Johnson's method, $92 \%$ with Dares method and $62 \%$ with obstetrical equation. It was $100 \%$ with Hadlock 2 equation, 96\% with Shepherd's and $86 \%$ with Warsoff equation Sensitivity for IUGR i.e. wt $<2.5 \mathrm{~kg}$ was low in clinical methods, highest was only $46.2 \%$ with Johnsons. In ultrasonic methods all the three equations had $100 \%$ sensitivity making ultrasound the preferred modality in diagnosing macrosomia.

Conclusions: The major finding of this study is that clinical estimation of fetal weight is as accurate as ultrasonographic method of estimation within normal range of birth weight Ultrasonographic methods was statistically more accurate with smaller mean errors and more within $10 \%$ of actual birth weight. Johnson formula gave most accuracy in clinical methods Ultrasound should be used to confirm clinical methods if IUGR or Macrosomia is suspected. No single method should be used if EBW is a part of decision but two or more methods should be combined.
\end{abstract}

Keywords: Expected fetal birth weight, Actual birth weight, Johnsons formulae, Dare formulae, Obstetrical equation, Hadlock equation, Warsoff equation, Shephard equation

\section{INTRODUCTION}

An accurate determination of fetal weight prior to delivery has a significant bearing on the management decisions during labor thereby improving perinatal outcome injuries in mother. Estimated fetal weight is required for management decisions in high risk pregnancies as in intrauterine growth retardation (IUGR), diabetic pregnancy, and vaginal birth after caesarean section and in borderline CPD. Antenatal assessment of fetal birth weight before delivery is required in planning the management, optimal route of delivery and the level of hospital where the delivery should be conducted. In large for date fetus, the potential 
complications associated with delivery include birth canal and pelvic floor injuries, postpartum hemorrhage, shoulder dystocia, brachial plexus injury and birth asphyxia.

There are a large number of clinical methods and ultrasonic formulae available in literature for predicting fetal birth weight with varying degrees of accuracy. Many studies are available in literature comparing clinical methods and ultrasonic methods among themselves and with one another. ${ }^{7-9}$ This study was an attempt to compare the accuracy of three clinical and three ultrasonic methods in Indian population. In a country like ours with diverse resource settings, the method with highest accuracy can be used depending on the available resource.

\section{METHODS}

This was a prospective non randomized cohort study done on 100 antenatal patients selected from labor room of a central government hospital, PGIMER, Dr RML hospital, New Delhi from Nov 2011 to Jan 2013, within a week of delivery.

\section{Inclusion criteria}

1. Confirmed dates

2. >34 week pregnancy

3. Cephalic presentation

\section{Exclusion criteria}

1. ruptured membranes

2. twin pregnancy

3. associated fibroid or ovarian tumor

4. Marked obesity BMI $>40 \mathrm{~kg} / \mathrm{m}$ )

5. IUD

EBW (expected birth weight) was calculated applying the 6 formulae, three clinical and three ultrasonic. If delivery did not occur in one week they were measured again.

The present study was approved by the institutional ethics and research review board. All the selected patients were explained the purpose of this study and their consent was taken for the same. The accuracy of EBW by the six methods was compared with the ABW (actual birth weight) which was recorded after delivery.

\section{Clinical estimation of fetal weight (EBW)}

After emptying the bladder, the patient was placed in dorsal position and dextro-rotation of gravid uterus was corrected. With the help of a flexible non stretchable measuring tape symphysio-fundal height measurement in $\mathrm{cm}$ from the upper border of the symphysis pubis up to the fundus was taken, with reverse side up to avoid bias. .Abdominal girth was measured in $\mathrm{cm}$ with the same measuring tape at the level of the umbilicus. PV examination was done to fine the station of head and to rule out ruptured membranes. Weight was calculated by these three formulas.

\section{Johnson's formula}

Weight in grams $=[$ SFH (symphysio-fundal height in cm) $-\mathrm{x}] \times 155$.

$X=13$, when presenting part is not engaged

$\mathrm{X}=12$, when presenting part is at 0 station

$\mathrm{X}=11$, when presenting part is at +1 station

\section{Dare's formula}

Weight in grams $=$ [symphysio-fundal height $(\mathrm{cm}) \times$ abdominal girth $(\mathrm{cm})$ ]

\section{Obstetrics equation}

Five Feto - maternal characteristics were used.

1. Gestational age at delivery

2. Parity

3. Maternal height

4. Maternal weight at 26 weeks

5. Maternal weight gain rate/day. Fetal sex was not seen according to PNDT act.

Birth weight $($ grams $)=$ [gestational age $(\mathrm{d}) \times$ $(9.36+0.000237 \times$ maternal height $(\mathrm{cms}) \times$ maternal weight at 26 weeks $(\mathrm{kg})+4.81 \times$ maternal weight gain rate $(\mathrm{kg} / \mathrm{d})$ $\times$ parity +1$]$.

\section{Ultrasonographic estimation of fetal weight}

The sonographic examination was performed with a 2-D Toshiba nemio X G ultrasound machine consisting of a trans abdominal convex array transducer with a frequency of $3.5 \mathrm{MHz}$ The information obtained included fetal dimensions particularly: BPD, FL and AC were measured according to standard techniques.

\section{Hadlock's formula 2 (already incorporated in ultrasound machine)}

$\log \mathrm{EBW}=1.335-0.0034(\mathrm{AC} \times \mathrm{FL})+0.0316(\mathrm{BPD})+$ $0.0457(\mathrm{AC})+0.1623(\mathrm{FL})$.

Calculation of fetal weight by the other two ultrasonographic formulae was done manually as they were not programmed in the ultrasound machine.

\section{Shepard's formula}

$\log \mathrm{EBW}=[-1.7492+0.166(\mathrm{BPD})+0.046(\mathrm{AC})-$ 2.646(AC $\times \mathrm{BPD}) / 1000]$ 


\section{Warsof2 formula}

$\log \mathrm{EBW}=[-1.599+0.144(\mathrm{BPD})+0.032(\mathrm{AC})-$ $\left.0.111\left(\mathrm{BPD}^{2} \times \mathrm{AC}\right) / 1000\right]$

The EBW was taken by all the methods within a week of delivery. If the delivery did not occur within a week of estimation of the fetal weight by various formulae, then the estimation was repeated and these fresh values were taken in to consideration.

After delivery, ABW (Actual Birth weight) was recorded immediately by using TANITA 1583 , digital weighing machine and EBW by various equations and $\mathrm{ABW}$ were compared.

\section{Statistical analysis}

Statistical analysis of the above results was calculated using by the SPSS program for Windows version 17.0 EBW was calculated by 6 methods and compared with ABW. Accuracy was measured by three methods

1. Absolute error

2. Absolute percentage error

3. Accuracy as within $10 \%$ of ABW. ABW was divided into four groups for statistical analysis $<2.5000 \mathrm{gms}$, 500-3.000 gms, 3.000-3.500 gms and more than 3.500 gms. The mean error represents the sum of positive (overestimation) and negative (underestimation) from actual birth weight.

Absolute error $=\mathrm{EFW}-\mathrm{ABW}$, absolute percentage error is calculated as EBW-ABW/ABWX100and the ratio by percentage of estimate within $10 \%$ of actual birth weight. The difference in proportion of estimates within $10 \%$ of actual birth weight was assessed by the chi-square test with $\mathrm{p}<0.05$ considered statistically significant.

\section{RESULTS}

Table 1: Distribution of actual birth weight among 4 groups.

\begin{tabular}{|ll|}
\hline Actual B W & Frequency in study population \% \\
\hline$<2500$ gm & $13 \%$ \\
\hline $2501-3000$ gm & $47 \%$ \\
\hline $3001-3500$ gm & $37 \%$ \\
\hline$>3500$ gm & $3 \%$ \\
\hline
\end{tabular}

The maternal age distribution was in the range of $21-38$ years. Mean age being $28.2 \pm 3.4$ years. The average gestational age at delivery (AGA) was 264.80 days (37 weeks +6 days) the range of $240-284$ day Mean actual birth weight was 2912.73 gm. range $1560-3800$ gms.

For statistical analysis actual birth weight of fetus was divided in to four groups $<2.500 \mathrm{gms}, 2.500-3.000 \mathrm{gms}$, 3.000-3.500gms and >3.500 gms. Maximum distribution of cases was in group 2501-3000 gm (47\%) (Table 1).Statistical analysis was done between actual birth weight and estimated birth weight.

Table 2: Number of cases over and underestimated by various methods.

\begin{tabular}{|llll|}
\hline \multicolumn{3}{|c|}{$\begin{array}{l}\text { Under } \\
\text { Estimated } \\
\text { Frequency }\end{array}$} & $\begin{array}{l}\text { Over } \\
\text { Estimated } \\
\text { Frequency }\end{array}$ \\
\hline S.no & Clinical Methods & \\
\hline 1 & Johnson's & $32 \%$ & $68 \%$ \\
\hline 2 & Dare's & $16 \%$ & $84 \%$ \\
\hline 3 & Obstetrics equation & $18 \%$ & $82 \%$ \\
\hline \multicolumn{3}{|c|}{ Ultrasonographic formulae } \\
\hline 1 & Hadlock's & $6 \%$ & $94 \%$ \\
\hline 2 & Shepard's & $74 \%$ & $26 \%$ \\
\hline 3 & Warsof's & $99 \%$ & $1 \%$ \\
\hline
\end{tabular}

In our study accuracy in all $\mathrm{ABW}$ within $10 \%$ of $\mathrm{ABW}$ was $94 \%$ with Johnson's method, $92 \%$ with Dares method and $62 \%$ with obstetrical equation. It was $100 \%$ with Hadlock 2 equation, $96 \%$ with Shepherd's and $86 \%$ with Warsoff equation.

In clinical methods Johnson's method had maximum tendency $(32 \%)$ to underestimate fetal weight increasing its sensitivity for diagnosing IUGR and in ultrasonic methods, Warsoff s equation $99 \%$ chance to under estimate fetal weight.

Dares overestimated in maximum number $(84 \%)$ and in ultrasonic methods Hadlocks equation (94\%) increasing their sensitivity to detect macrosomia (Table 2).

Among the clinical formulae Johnson's formula was showing least mean differences (45.60 gms) from ABW. Among the three ultrasonographic equations Hadlock's formula was showing least mean differences from actual birth weight (26.88 gms). Obstetric equation \& Warsof formula was showing mean differences of $210.80 \mathrm{gm} \mathrm{\&}$ 202.14 gm (Figure 1). All clinical formulae were showing more mean absolute \% error in group <2500 gm. However Obstetric equation was showing maximum mean absolute \% error in each group than other, with zero specificity for IUGR. In all ultrasonographic formulae Hadlock's was showing least mean absolute \% error in each group except in $>3500 \mathrm{gm}$. Warsof formula was showing least absolute error than Hadlock's in group $>3500$ gm (Figure $2 \& 3$ ). All USG formulae were more correlated to ABW as compare to clinical formulae.

Sensitivity for IUGR i.e. wt $<2.5 \mathrm{~kg}$ was low in clinical methods; highest was only $46.2 \%$ with Johnsons method and 0 for obstetrical equation. However among ultrasonic methods highest sensitivity was with warsoff $(100 \%)$ and lowest was for Hadlocks method (84.6\%). Clearly ultrasonic methods were better in predicting IUGR. 
Specificity was $100 \%$ for all three clinical methods. In ultrasonic methods, specificity was $100 \%$ for Hadlocks method (Figure 4).

Table 3: Various ultrasonic equations used to predict fetal weight.

\begin{tabular}{|c|c|c|c|}
\hline No. & Author & Year & Equation \\
\hline 1 & Campbell & 1975 & $\begin{array}{l}\mathrm{LnBw}=4.564+ \\
0.0282(\mathrm{AC})- \\
0.00331(\mathrm{AC})^{2}\end{array}$ \\
\hline 2 & Warsof & 1977 & $\begin{array}{l}\log 10 \mathrm{Bw}=-1.599+ \\
0.32(\mathrm{AC}) \\
-0.000111(\mathrm{BPD})^{2}(\mathrm{AC})\end{array}$ \\
\hline 3 & Shepard & 1982 & $\begin{array}{l}\log 10 \mathrm{Bw}=-1.7492+ \\
0.166(\mathrm{BPD})+0.046= \\
0.002546(\mathrm{AC})(\mathrm{BPD})\end{array}$ \\
\hline 4 & $\begin{array}{l}\text { Hadlock 1- } \\
\text { AC,FL }\end{array}$ & 1985 & $\begin{array}{l}\log 10 \mathrm{BW}=1.304+ \\
(0.05281 \mathrm{X} \mathrm{AC})+ \\
(0.1938 \mathrm{XFL})-(0.004 \\
\text { XAC x FL }\end{array}$ \\
\hline 5 & $\begin{array}{l}\text { Hadlock II- } \\
\text { BPD, AC,FL }\end{array}$ & 1985 & $\begin{array}{l}\log 10 \mathrm{BW}=1.335- \\
(0.0034 \mathrm{X} \mathrm{AC} X \mathrm{FL})+ \\
(0.0316 \mathrm{BPD})+ \\
(0.04 \mathrm{~s} 7)(\mathrm{AC}) \\
+(0.1623 \text { X FL })\end{array}$ \\
\hline 6 & $\begin{array}{l}\text { Hadlock III- } \\
\text { HC,AC,FL,X } \\
\text { HC }\end{array}$ & 1985 & $\begin{array}{l}\log 10 \mathrm{BW}=7.326- \\
(0.00326 \text { X AC X FL }) \\
+(0.0107+(0.0438 \\
\text { XAC })+(0.1 \mathrm{~s} 8 \text { XFL }\end{array}$ \\
\hline 7 & $\begin{array}{l}\text { Hadlock IV- } \\
\text { BPD,HC,AC, } \\
\text { FL }\end{array}$ & 1985 & $\begin{array}{l}\log 10 \\
\text { BW=0.3596+(0.00061 } \\
\text { XBPDXAC })+ \\
(0.0424 X A C) \\
+(0.174 X F L)+ \\
(0.0064 X H C)- \\
(\text { O.OO386XACX }\end{array}$ \\
\hline 8 & Nzeh 1 & 1992 & $\begin{array}{l}\log 10 \mathrm{Bw}=0.470+ \\
0.488 \log \mathrm{BPD}+ \\
0.554 \log 10 \mathrm{FL}+ \\
1.377\end{array}$ \\
\hline 9 & Nzeh 2 & 1992 & $\begin{array}{l}\log 10 \mathrm{Bw}=0.326+ \\
0.0045(\mathrm{SDI})+ \\
0.383 \log 10 \mathrm{BPD}+ \\
0.614 \log 10 \mathrm{FL}+\end{array}$ \\
\hline 10 & Combs & 1993 & $\begin{array}{l}\mathrm{Bw}= \\
0.23718(\mathrm{AC})^{2}(\mathrm{FL})+ \\
0.03312(\mathrm{HC})^{3}\end{array}$ \\
\hline
\end{tabular}

For macrosomia, sensitivity was $100 \%$ for Dares method and in ultrasonic methods all the three equations had 100 $\%$ sensitivity making ultrasound the preferred modality in diagnosing macrosomia. Among clinical methods specificity for macrosomia was highest for Johnson's methods $98.6 \%$ and was above $95 \%$ for all three ultrasonic formulae (Figure 5).

All clinical formulae was showing more absolute maximum error in group $<2500 \mathrm{gm}$ than ultrasonic methods. Obstetric equation was showing more maximum absolute error in each group (Figure 6).

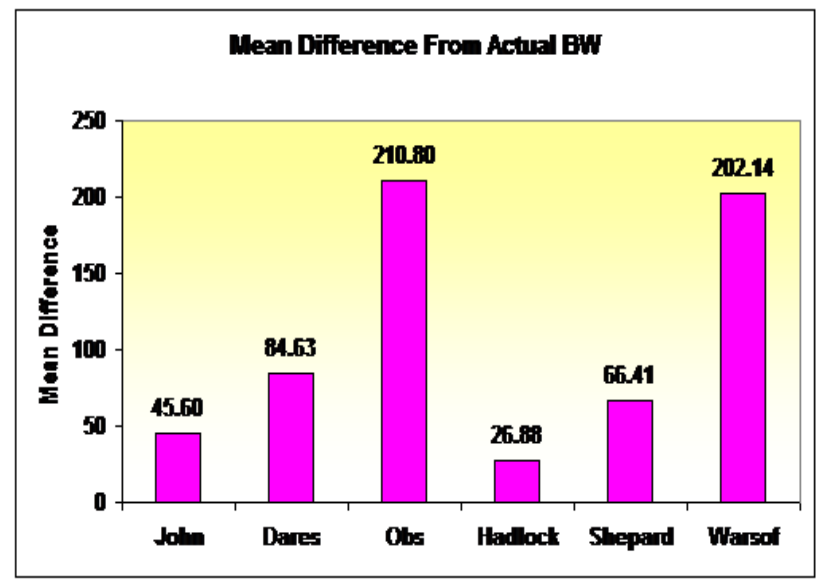

Figure 1: Mean differences from actual birth weight by various formulae.

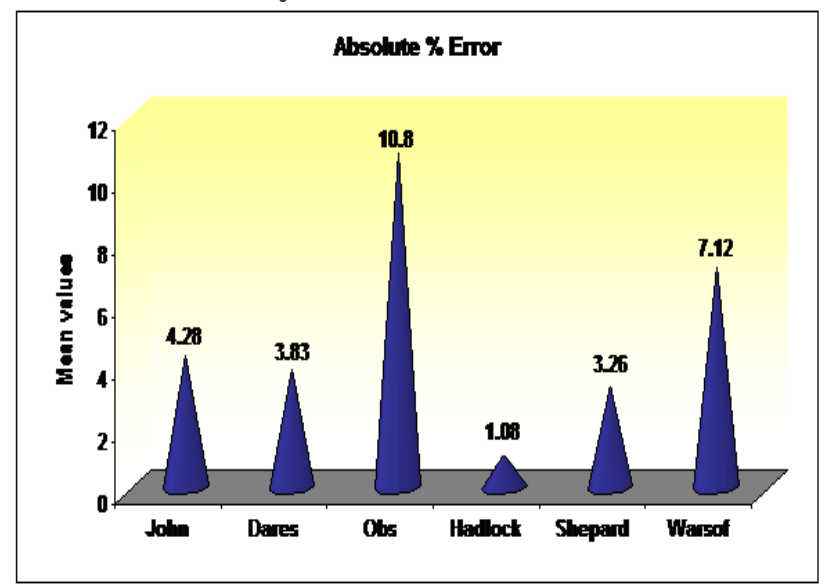

Figure 2: Absolute \% error in each formulae.

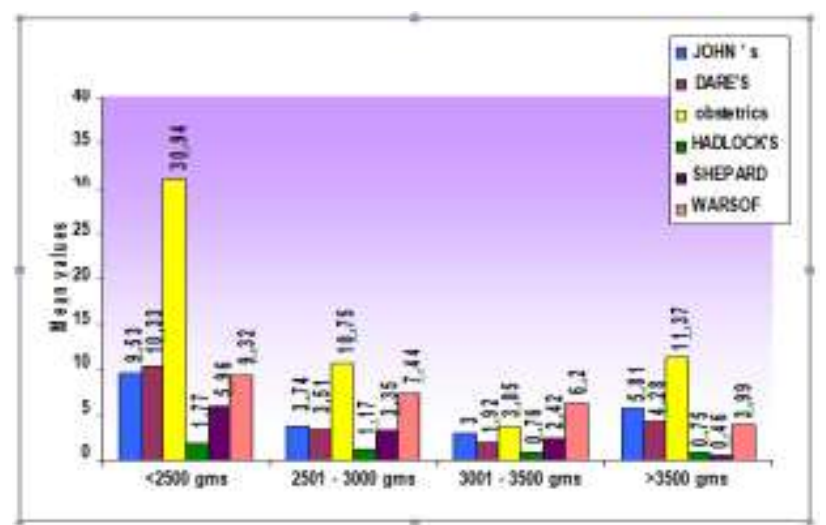

Figure 3: Mean absolute \% error in each group various formulae.

In all the three used ultrasonographic formulae, Hadlock's formula was showing least absolute maximum error in each group except in $>3.5 \mathrm{~kg}$ followed by Shepard's. Hadlock's formula was showing least absolute 
maximum error than Dare's formula. All ultrasonographic formulae were showing absolute maximum error in group $2501-3000 \mathrm{gm}$, which had the maximum distribution in study group. Using Hadlock's formula, the maximum error in various fetal weight groups was most marked in <2500 gms.

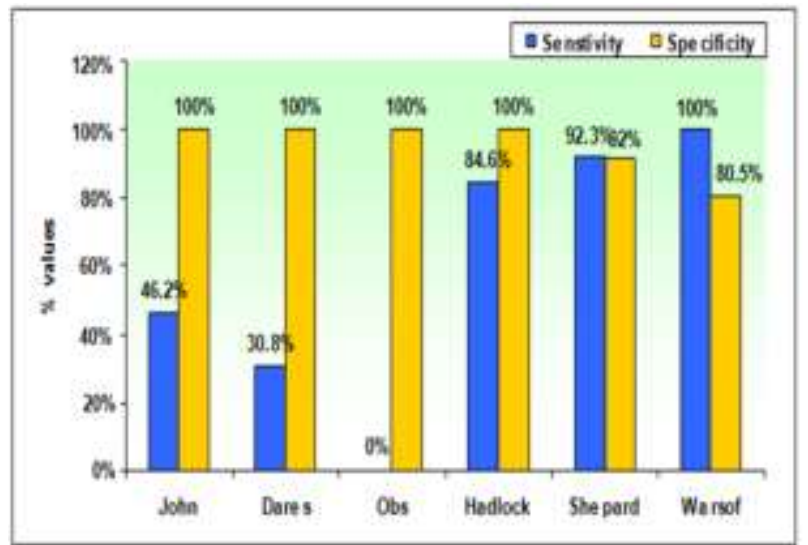

Figure 4: Sensitivity $\&$ specificity in detecting $<2500$ gm birth weight.

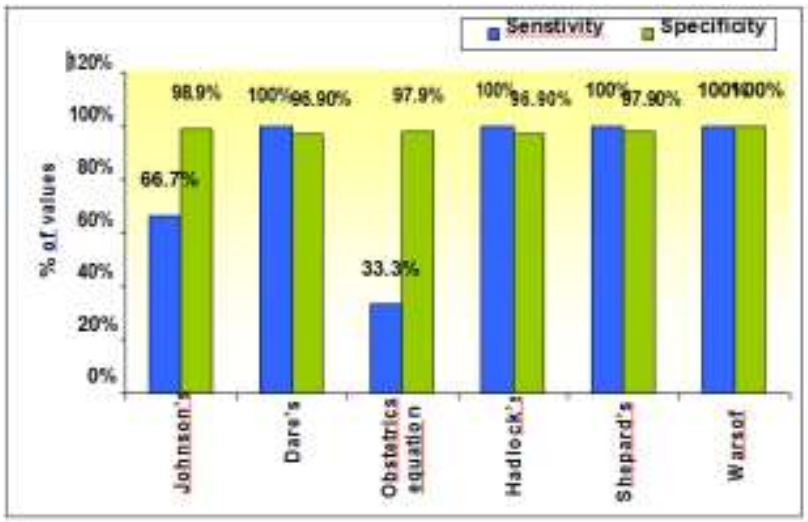

Figure 5: Sensitivity \& specificity in detecting $>3500$ gm birth weight.

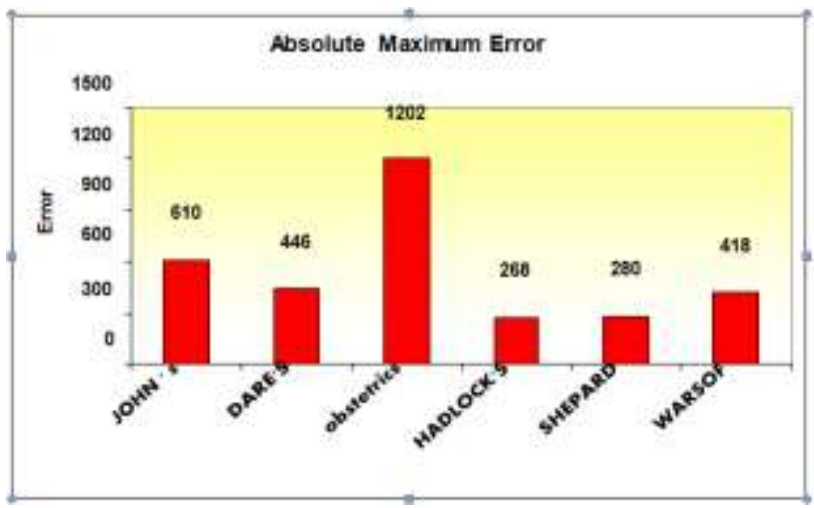

Figure 6: Absolute maximum error by various formulae.
There was significant co relation between SFH (symphsio-fundal height) and ABW, p<0.005 and $\mathrm{r}=0.879$.

\section{DISCUSSION}

The importance of fetal birth weight estimation cannot be over emphasized as both low birth weight and excessive fetal weight at delivery are associated with an increased risk of maternal and neonatal complications during labor and puerperium. It was in 1954 that Johnson used SFH in predicting EFW. ${ }^{1}$ In 1990 Dare included his method of combining abdominal girth and $\mathrm{SFH}^{2}$ Dawn used his modification by measuring skin fold thickness by calipers and used the formula weight (grams) = longitudinal diameter of the uterus $x$ transverse diameter of the uterus $\mathrm{x} 1.44 / 2$. If Double abdominal wall thickness was more than $3 \mathrm{~cm}$, the excess was deducted from fundal height in cms A obstetrical equation was formulated by Shittu et al in 2007 and it was used in our study using multiple maternal parameters like maternal height, weight, and also rate of weight gain. It also included prenatal fetal sex which was excluded from our study (value given as 0$){ }^{3}$

Various equations have been used in ultrasound in the last three decades to estimate fetal birth weight. More than 30 equations are available in literature namely Hadlock 1-4, Shephard, Warsoff, Cambell, woo 1; woo 2 with varying accuracy (Table 3). Our study showed a clear role of clinical methods in estimating fetal weight at par with ultrasonic equations. In estimating weight $<2500$ $\mathrm{gm} \&>3500 \mathrm{gm}$ there is a role of ultrasound as additional tool Sensitivity and Specificity of ultrasonography formulae were more in $<2500 \mathrm{gm}$ and $>3500 \mathrm{gm}$ as compared to clinical method. All the three USG formulas had $100 \%$ sensitivity in predicting fetal weight more than $3.5 \mathrm{Kg}$. Among clinical methods in our study, Dares formula was $100 \%$ sensitive in predicting weight $>3.5 \mathrm{Kg}$ Kacem et al used MRI to predict EBW and found it more accurate then USG however it cannot be routinely used. ${ }^{5}$

In our study we found Johnson equation giving a fair degree of accuracy compared to ultrasonic methods which had lower error at extremes of fetal weight. Obstetrical equation did not give good accuracy; however Shittu et al found it quite accurate in a study conducted in Nigeria. ${ }^{3}$ Among ultrasonic equations Hadlock 2 gave good accuracy compared to other two ultrasonic equations. Literature is flooded with varying comparisons of clinical and ultrasonic. Most find comparable accuracy among clinical and ultrasonic methods.

Since Chauhan et al first published their study in 1992, several studies have confirmed that maternal estimates are as accurate as ultrasound estimates. ${ }^{6}$ The studies of Hendrix et al and Raman et al showed that clinical estimation was more accurate than sonographic methods. Watson et all found no difference even at extremes of weight at term. ${ }^{7}$ In another study by Chauhan et al in 1998 they found similar accuracy between clinical and 
ultrasonic methods except in birth weight $<2.500 \mathrm{gms}^{9}$ The study by Bhandari et al in Karnataka India and Regina et al in 2005 in Brazil found similar accuracy in the clinical and ultrasonic estimates Titapani in 1999 and Mehdizadeh in 2000, in an Iranian population found similar accuracy between clinical and ultrasonic methods. ${ }^{12,16-18}$

Dudley used eleven ultrasonic prediction models and concluded that there was no preferred method and magnitude of errors were a major obstacle to confident use in clinical practice. ${ }^{20}$ The study by Burd in 2009 used fourteen different formulae in ultrasound for predicting fetal weight and concluded wide variation in sensitivity and specificity with no formula showing any superiority over rest compared with clinical methods no advantage was seen in ultrasound in extremes of fetal weight by Hargreaves in a study published in $2011 .^{22,23}$ Though not validated recent studies done using 3,4 D USG measuring foetal thigh measurements are showing significant accuracy in macrosomic baby MRI is another costly alternative which cannot be freely used routinely. ${ }^{24}$

Among the measures of accuracy used in our study simple error was not a good predictor of accuracy and was misleading as because it is a sum of over and underestimates. In contrast absolute error and percentage error and weight within $10 \%$ are better indicator of accuracy as they represent variability regardless of direction. There were few limitations in our study. The drawback was that it tested hadlock formula which was developed in 1985. Although some authors have advocated the use of other equations, a recent systematic review reported that the accuracy of Hadlock's formula did not differ significantly from other models ${ }^{23}$ Another big drawback of our study was that it did not have macrocosmic babies in large number only three had ABW >3.500 gms In our study we took macrosomia as $>3.5 \mathrm{~kg}$ as we did not get any newborn weighing more than $4 \mathrm{~kg}$ in our study group. It was a general population based study and more macrosomic babies are needed to draw any conclusion from this study assessment in large birth weight and also the other extreme low birth weight. In clinical methods the confounders were maternal obesity and hydramnios.

The reason why ultrasound has its limitations in 2-D because it may be noted that only spatial measurements are made in ultrasound whereas fetal mass is a function of fetal volume and density and density of fetus at term is not constant. Routine 2 D USG has its limitations in measuring volume. Also $15 \%$ of fetal birth weight at term is adipose tissue which is increased in macrosomic babies of diabetic mothers.

The positive point in our study was that it aimed to compare two modalities available in two different settings namely low cost easy estimation which could be done by residents in low resource settings and at the same time compared it with available ultrasound modality in high resource setting. The drawback was that it tested a hadlock 2 formula which was developed in 1985 and many new equations have come up which need to be tested in specific population.

\section{CONCLUSIONS}

The major finding of this study is that clinical estimation of fetal weight is nearly as accurate as ultrasonographic method of estimation within normal range of birth weight. An ultrasonographic method was statistically more accurate with smaller mean errors and more within $10 \%$ of actual birth weight. Johnson formula gave most accuracy in clinical methods Hadlock 2 also proved to be more accurate in ultrasonic equations.

It is recommended that symphysial fundal height be routinely incorporated in antenatal care and utilized at term to measure EBW by Johnson's method. Ultrasound should be used to confirm clinical methods if IUGR or Macrosomia is suspected. No single method should be used if EBW is a part of decision but two or more methods should be combined. The equation fed into ultrasonic machine should also be known. More studies using the newer methods like thigh measurements using 3-D ultrasound need to be done specially for extremes of fetal weight.

\section{ACKNOWLEDGMENTS}

Authors would like to thank to Dr Pushpa Singh, Head of Ob-Gyn, Dr Umesh Garga Head of department of Radiology, PGIMER, Dr RML Hospital, New Delhi. India.

Funding: No funding sources

Conflict of interest: None declared

Ethical approval: The study was approved by the Institutional Ethics Committee

\section{REFERENCES}

1. Johnson RW, Toshach CE. Estimation of fetal weight using longitudinal mensuration. Am J Obstet Gynecol. 1954;68(3):891-6.

2. Dare FO, Ademowore AS, Ifaturoti OO. The value of symphysio-fundal height/abdominal girth measurements in predicting fetal weight. Int $\mathbf{J}$ Gynaecol. 1990;31:243-8.

3. Shittu AS, Kutti O, Orji EO. Clinical versus sonographic estimation of fetal weight in south west Nigeria. Jhealth popul nutr. 2007;25(1):14-23.

4. Hadlock FP, Harrist RB, Sharman RS. Estimation of fetal weight with the use of head, body, and femur measurements-a prospective study. Am J Obstet Gynecol. 1985;151(3):333-7.

5. Kacem Y, Cannie MM, Kadji C et al. Fetal weight estimation: comparison of two-dimensional US and MR imaging assessments Radiology. 2013;267(3):902-10. 
6. Chauhan SP, Lutton PM, Bailey KJ. Intrapartum clinical, sonographic, and parous patients' estimates of newborn birth weight. Obstet Gynecol. 1992;79(6):956-8.

7. Raman S, Urquhart R, Yusof M. Clinical versus ultrasound estimation of fetal weight. Aust N Z J Obstet Gynaecol. 1992;32(3):196-9.

8. Banerjee K, Mittal S, Kumar S. Clinical vs. ultrasound evaluation of fetal weight. Int J Gynaecol Obstet. 2004;86(1):41-3.

9. Chauhan SP, Hendrix NW, Magann EF. Limitations of clinical and sonographic estimates of birth weight: experience with 1034 parturients. Obstet Gynecol. 1998;91(1):72-7.

10. Fernández-Castro F, Laredo-Rodríguez A, Hernández-Herrera R. Sensitivity and predictive value of the Johnson and Toshach method to estimate fetal weight. Rev Med Inst Mex Seguro Soc. 2006;44(4):309-12

11. Valenzuela Tinoco E, Puente González H, de Dios Maldonado Alvarado J. Prediction of fetal weight by the Johnson-Toshach method. Ginecol Obstet Mex. 1998;66:420-2.

12. Bhandary Amritha A, Pinto patric J, Shetty Ashwin P. Comparative study of various methods of fetal weight estimation at term pregnancy. J Obstet Gynecol Ind. 2004;54(4):336-9.

13. Japarath $\mathrm{P}$, Wiboolphan $\mathrm{T}$. Comparison of the accuracy of fetal weight estimation using clinical and sonographic methods. J Med Assoc Thai. 2004;87(3).

14. Kumari A, Goswami S, Mukherjee P. Comparative Study of Various Methods of Fetal Weight Estimation in Term Pregnancy. J South Asian Feder Obst Gynae. 2013;5(1):22-5.

15. Nahar N, Akhter N, Hoque ME et al. Comparative study between clinical and sonographic, estimation of weight in third trimester of pregnancy and its relationship with actual birth weight. Mymensingh Med j. 2008;17(2):157-63.

16. Torloni MR, Sass N, Sato JL, Renzi AC, Fukuyama M, Rubia de Lucca P. Clinical formulas, mother's opinion and ultrasound in predicting birth weight. Sao Paulo Med J. 2008;126(3):145-9.

17. Mehdizadeh A, Alaghehbandan R, Horsan $H$. Comparison of clinical versus ultrasound estimation of fetal Weight. Amj Perinatol. 2000;17(5):233-6.

18. Titapant V, Chawanpaiboon S, Mingmitpatanakul K. A comparison of clinical and estimation of fetal Weight. J Med Assoc Thai. 2001;84(9):1251-7.

19. Sherman DJ, Arleli S, Tovbin J. A comparison of clinical and ultra sonic estimation of fetal weight. Obstet Gynecol. 1998;91(2):212-7.

20. Dudley NJ. A systematic review of the ultrasound estimation of fetal weight. Ultrasound Obstet Gynecol. 2005;25(1):80-9.

21. Ugwa EA. Advances in clinical estimation of fetal weight before delivery. Niger J Basic Clin Sci. 2015;12:67-73.

22. Burd, Srinivas. Is sonographic assessment of fetal weight influenced by formula selection? J Ultrasound Med. 2009;28(8):1019-24.

23. Hargreaves K, Cameron M, Edwards H, Gray R. Is use of symphysis-fundal height measurement and ultrasound examination effective in detecting small or large fetuses? Journal of obstetrics and Gynaecology. 2011;31(5):380-3.

24. Lee W, Balasubramaniam M, Russel L, Yeo L. New Fetal Weight Estimation Models Using Fractional Limb Volume Ultrasound in Obstetrics \& Gynecology. 2009:556-65.

Cite this article as: Malik R, Thakur P, Agarwal G. Comparison of three clinical and three ultrasonic equations in predicting fetal birth weight. Int $\mathbf{J}$ Reprod Contracept Obstet Gynecol 2016;5:210-6. 